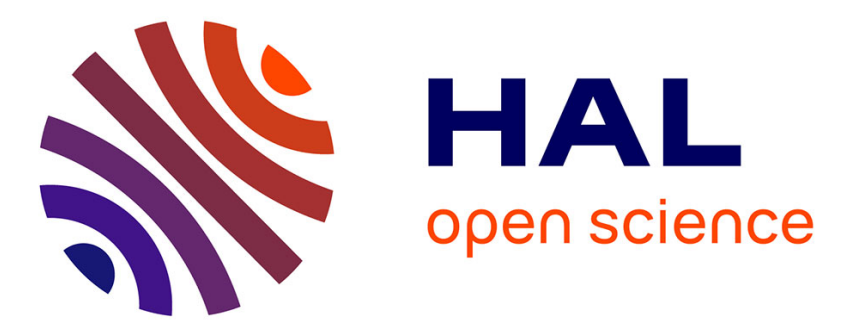

\title{
Reducing the adhesion between surfaces using surface structuring with PS Latex particle.
}

Jérôme Dejeu, Mikhael Bechelany, Laetitia Philippe, Patrick Rougeot, Johann Michler, Michaël Gauthier

\section{- To cite this version:}

Jérôme Dejeu, Mikhael Bechelany, Laetitia Philippe, Patrick Rougeot, Johann Michler, et al.. Reducing the adhesion between surfaces using surface structuring with PS Latex particle.. Applied Materials \& Interfaces, 2010, 2 (6), pp.1630-1636. 10.1021/am100156c . hal-00495002

\section{HAL Id: hal-00495002 \\ https://hal.science/hal-00495002}

Submitted on 24 Jun 2010

HAL is a multi-disciplinary open access archive for the deposit and dissemination of scientific research documents, whether they are published or not. The documents may come from teaching and research institutions in France or abroad, or from public or private research centers.
L'archive ouverte pluridisciplinaire HAL, est destinée au dépôt et à la diffusion de documents scientifiques de niveau recherche, publiés ou non, émanant des établissements d'enseignement et de recherche français ou étrangers, des laboratoires publics ou privés. 


\title{
Reducing the adhesion between surfaces using surface structuring with PS latex particle
}

\author{
Jérôme Dejeu, ${ }^{\dagger}$ Mikhael Bechelany, ${ }^{*, \$}$ Laetitia Philippe, $^{\ddagger}$ Patrick Rougeot, ${ }^{\dagger}$ \\ Johann Michler, ${ }^{\ddagger}$ and Michaël Gauthier ${ }^{*} \dagger$ \\ FEMTO-ST Institute, UMR CNRS 6174 - UFC / ENSMM / UTBM, 24 rue Alain Savary, 25000 \\ Besançon, France, and EMPA-Materials Science \& Technology, Laboratory for Mechanics of \\ Materials and Nanostructures, Feuerwerkerstrasse 39, CH-3602 Thun, Switzerland
}

\begin{abstract}
The adhesion between a micro-object and a micro-gripper end-effector is an important problem in micromanipulation. Cancelling or reduction this force is a great challenge. This force is directly linked to the surface chemical structure of the object and the gripper. We propose to reduce the adhesion force by using a self-assembled monolayer structuring on one surface. The surface was structured by polystyrene latex particles (PS particles) with radii from 100 to $1500 \mathrm{~nm}$. The adhesion force measurements obtained by AFM were compared to a multisphere van der Waals force model. The model suggests the existence of an optimal value of the sphere radius which minimizes the adhesion. In that case, the pull-off force is reduced to $20 \mathrm{nN}$ by the PS particles layer with a radius of $45 \mathrm{~nm}$. A wide range of applications, in the field of telecommunications, bioengeneering, and more generaly speaking MEMS can be envisaged for these substrates.
\end{abstract}

\footnotetext{
${ }^{\dagger}$ FEMTO-ST Institute

‡EMPA
} 
KeyWord: surface structuring, adhesion force, pull-off forces, PS latex particle, Micromanipulation

\section{Intoduction}

The miniaturisation of devices in the fields of telecommunication, bio-engineering, telecommunication and more generally speaking of Micro-Electro-Mechanical-Systems (MEMS) is increasing and the assembly of these microproducts is a great challenge because of the microscopic size of the components. ${ }^{1}$ During robotic micro-assembly, microparts have to be picked, moved, and released. Other tasks like insertion, alignment and guiding often must also be done. A contact between two surfaces, for example, gripping tools and a manipulated object or a substrate and a manipulated object, generates adhesion forces and the influence of this force increases as the micro-object size decreases. ${ }^{2-4}$ The manipulation of a micro-object requires handling, positioning, and release without disturbances of the surface forces including electrostatic, van der Waals or capillary forces.

Current microhandling methods are able to improve micromanipulation but the object behaviour is always disturbed by adhesion and thus the repeatablity and reliability is still low. 5,6 The required force to separate two surfaces is commonly called the "pull-off" force. The "pull-in" force is the attractive force between two objects when they approach closely. The pull-off forces are not well understood and must be studied further to enable the advent of reliable micromanipulation techniques. Current methods to measure micro/nanoforces between surfaces are the Surface Force Apparatus (SFA), ${ }^{7,8}$ the Atomic Force Microscope (AFM), ${ }^{9-11}$ capacitive force sensors ${ }^{12}$ or nanoindentation testers. ${ }^{13,14}$

The modeling of pull-off force are mainly based on two different approaches based on the surface energies on the contact, ${ }^{15-18}$ or on the integration of the van der Waals forces between objects ${ }^{19-21}$ and on some hybrid approaches between both. ${ }^{23,24}$

We propose to control the surface forces between objects and grippers by surface nanostruc- 
ture arrays in order to decrease the adhesion. The authors have already demonstrated that surface chemical functionalisation can decrease adhesion forces ${ }^{9}$ and switch them ${ }^{25}$ in air and dry mediums respectively. Thanks to the surface structures, we can reduce the contact area between the gripper and the objects, and in turn this will decrease contact and van der Waals forces. Also, we can engineer specific properties of the gripper such as using electrically conductive materials to minimize electrostatic force. In practice, the approach for surface structuring can be categorized into two directions: top-down and bottom-up approaches. Top-down approaches encompass lithographic and template-based techniques, ${ }^{26}$ and plasma treatment of the surfaces. ${ }^{27}$ Bottomup approaches involve mostly self-assembly and self-organization ${ }^{28}$ as for instance chemical deposition, ${ }^{29}$ layer-by-layer (LBL) deposition, ${ }^{30}$ hydrogen bonding, ${ }^{31}$ and colloidal assemblies. ${ }^{32}$ There are also methods based on the combination of both bottom-up and top-down approaches, for example, casting of polymer solution and phase separation, ${ }^{33}$ and electrospinning. ${ }^{34}$ Among these methods, the application using two-dimensional (2D) colloidal crystals, "natural lithography", which has been suggested by Deckman and Dunsmuir, ${ }^{35}$ has attracted attention due to it being a relatively easy process in comparison with conventional lithography. ${ }^{35}$ Based on such a process, uniformly sized microstructures could be produced on a substrate using a monolayer coating of colloidal spheres instead of a conventional resist. In recent years, various techniques, which are often called "colloidal lithography" or "nanosphere lithography", have been reported for nano/microfabrication or nano/micropatterning of a wide variety of solid substrates including semiconductors, ${ }^{36-40}$ metals ${ }^{41}$ and ceramics.

The objective of this article is to measure and to model the adhesive force (pull-off) between a cantilever and a silicon surface strutured with regular arrays of polystyrene (PS) latex particles. The spheres are choosen because they allow us to develop a model to predict the evolution of the adhesion as a function of the scale effect. The adhesive force must be determinated during the micromanipulation task. First, we present a surface patterning method then the adhesion measurement methodology. This is followed by a discussion of the force-distance measurements that were performed by AFM with a sphere glued on the cantilever extremity. Finally, the results are 
discussed in view of their applications in micromanipulation tasks. The array of spheres allows us to identify a particular size that achieves a minimal pull-off force.

\section{Materials and Methods}

\section{Surface structuring}

Three different types of commercially available PS microsphere suspension $\left(r_{2} \approx 100 \mathrm{~nm}, 2.53 \mathrm{wt}\right.$ $\%$ aqueous dispersion), $\left(r_{2} \approx 500 \mathrm{~nm}, 2.53 \mathrm{wt} \%\right.$ aqueous dispersion) and ( $r_{2} \approx 1500 \mathrm{~nm}, 2.53 \mathrm{wt} \%$ aqueous dispersion) were used (Polysciences, Inc., Eppelheim, Germany ) as received. Acetone, $\mathrm{NH}_{4} \mathrm{OH}(25 \%)$ and $\mathrm{H}_{2} \mathrm{O}_{2}$ (30\%) were purchased from Aldrich and p-type Si wafers (5-10 $\Omega . \mathrm{cm}$, (111) crystal orientation) of dimensions $1.5 \mathrm{~cm}^{2}$ from Silicon Materials were used as substrates. Prior to patterning, the Si specimens were precleaned in acetone to remove the organic contaminants, and were then heated in air at $600{ }^{\circ} \mathrm{C}$ for $10 \mathrm{~min}$ to increase the thickness of the oxide layer. After that, the substrate was treated by the conventional RCA I process to obtain a hydrophilic Si surface, i.e. a treatment with a 1:1:5 solution of $\mathrm{NH}_{4} \mathrm{OH}(25 \%), \mathrm{H}_{2} \mathrm{O}_{2}(30 \%)$, and water at $80^{\circ} \mathrm{C}$ for 15 min just before use was carried out. ${ }^{40}$ Note that: Piranha solution is highly corrosive and extremely reactive with organic substances, therefor gloves, goggles, laboratory coats, and face shields are used while handling. Hydrophilic surfaces were formed by the terminal silanol ( $\mathrm{SiOH})$ groups. After this pre-treatment, a monodisperse suspension of polystyrene (PS) microspheres (Polysciences, Inc.) was spin coated onto the substrate and after the suspension was dried in air at room temperature (RT). The spin coating was performed by controlling the parameters (time, speed and cycles) and are detailed in Table 1. After the complete evaporation of the solvent, the Si substrate with the binary colloidal crystals formed by the spheres was heated at $100^{\circ} \mathrm{C}$ for 1 $\mathrm{h}$, which is higher than the glass transition point $\left(\mathrm{Tg} \approx 93^{\circ} \mathrm{C}\right)$ of polystyrene. This was done to increase the adhesive stability of the PS spheres on the Si surface.

After spin coating, the PS spheres organised on the Si substrate were characterised by scanning electron microscopy (SEM, Hitachi S-4200, S-4800). 
Table 1: Spin coating parameters versus the PS particles radius.

\begin{tabular}{|c|c|c|}
\hline$r_{2}$ & step 1 & step 2 \\
\hline $100 \mathrm{~nm}$ & $200 \mathrm{rpm} / 10 \mathrm{~s}$ & $1000 \mathrm{rpm} / 30 \mathrm{~s}$ \\
\hline $500 \mathrm{~nm}$ & $300 \mathrm{rpm} / 10 \mathrm{~s}$ & $500 \mathrm{rpm} / 30 \mathrm{~s}$ \\
\hline $1500 \mathrm{~nm}$ & $300 \mathrm{rpm} / 10 \mathrm{~s}$ & $400 \mathrm{rpm} / 30 \mathrm{~s}$ \\
\hline
\end{tabular}

\section{Force distance measurement by Atomic Force Microscopy}

Characterisation of the pull-off force was performed with a commercial atomic force microscope (stand-alone SMENA scanning probe microscope NT-MDT). The experiments were done under a controlled environment with a laminar flow (humidity $30 \%$ and $25^{\circ} \mathrm{C}$ ) on the Nanorol platform Station. The "nanorol platform" can be used by external person. The availability and the booking of the station is consultable via internet at: http:// hanorol. cnrs.fr/events.php.

The rectangular silicon AFM cantilever, whose stiffness is $0.3 \mathrm{~N} / \mathrm{m}$, was fixed and the substrate moved vertically. The same cantilever was used for all experiments. As the objective of this work is to improve the reliability of micro-object manipulation, interactions have been studied between a micrometric sphere and a plane. Measurements were in fact performed with a cantilever where a borosilicate sphere $\left(r_{1}=5 \mu \mathrm{m}\right.$ radius) was glued in place of the standard AFM tip (Ref.:PT.BORO.SI.10, company Novascan Technologies, Ames, IA, USA). Ten measurements were done at different locations on the same sample with a driving speed of $200 \mathrm{~nm} / \mathrm{s}$.

\section{Typical force-distance curve}

The attractive and adhesive force-distance curve is presented in Figure 1. In this case, an attractive force (pull-in force) is measured when the sphere is coming close to the substrate (near -20 nN, Figure 1). In Figure 1, we are clearly measuring a pull-off force which represents the adhesion between the borosilicate sphere on the tip and the substrate. In this example, the pull-off force reaches $-1.1 \mu \mathrm{N}$. This behaviour represents an attraction between the surfaces. 


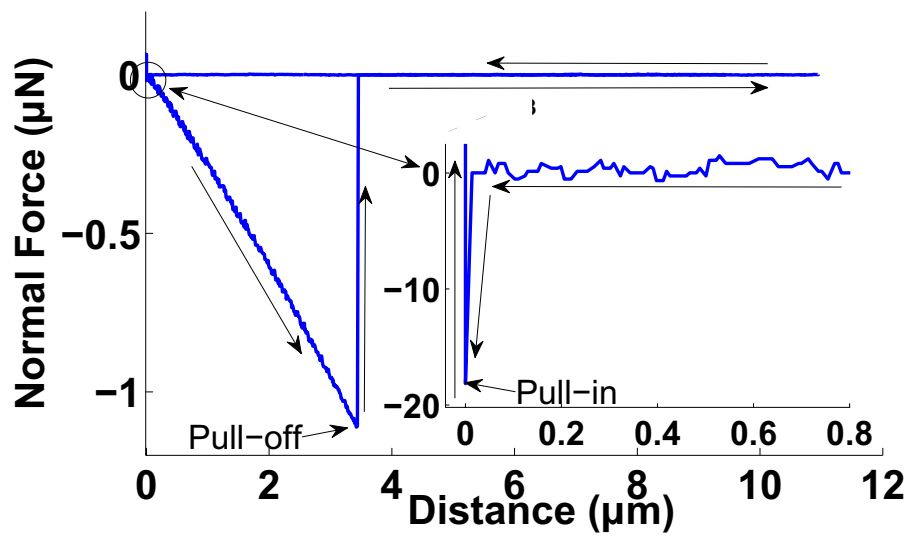

Figure 1: Attractive and adhesive typical force-distance curves between surface and cantilever (stiffness: $0.3 \mathrm{~N} / \mathrm{m}$ )

\section{Results and discussion}

\section{Microscopy}

Monolayers of polystyrene PS spheres were created by spin coating PS spheres radius of $100 \mathrm{~nm}$, $500 \mathrm{~nm}$ and $1500 \mathrm{~nm}$ (Figure 2) onto a (111) $\mathrm{Si} / \mathrm{SiO}_{2}$ substrates. The heating of the structured surface was necessary in order to adhear the particle to the substrate. Indeed, without this step, it is impossible to scan the sample with particles because they moved along the surface.

The specimens were successfully coated with large domains of defect-free packing over the entire substrate surface. In Figure 2, the spheres arranged themselves into a close-packed structure of two-dimensional ordered lattices due to attractive capillary forces.

\section{Force measurement}

Experiments have been done in a dry controlled medium with a structured surface by PS latex particles and a borosilicate sphere on the cantilever tipless AFM cantilever. The measurements were repeated ten times on the same points and at different points of the sample. Additionally measurements on the different particles sizes have been done. Examplers of the force distance measurements in each sample are presented in Figure 3 and discussed below. 


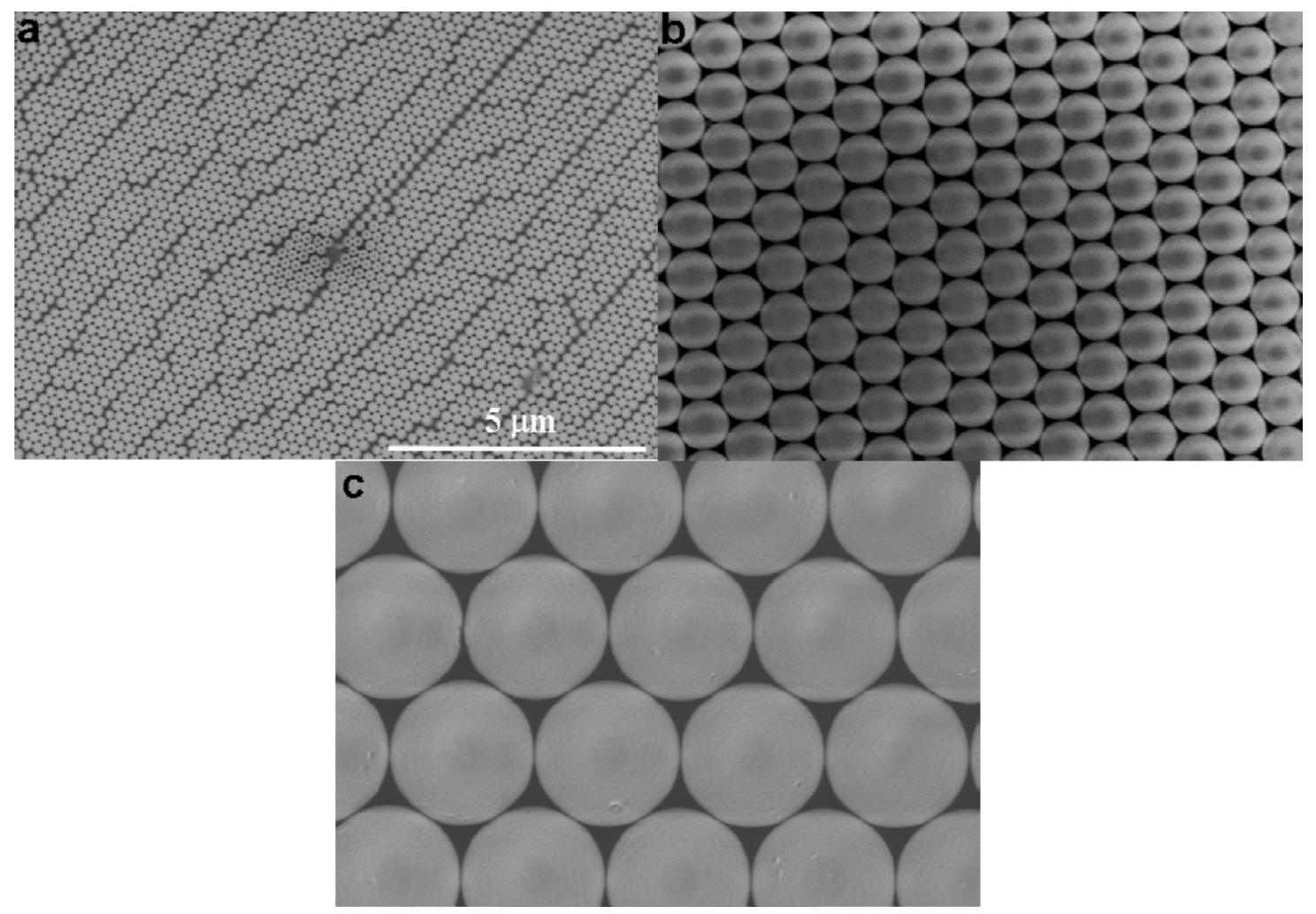

Figure 2: SEM images of a self assembled monolayer of PS spheres with a radius of (a) $100 \mathrm{~nm}$, (b) $500 \mathrm{~nm}$ and (c) $1500 \mathrm{~nm}$ 


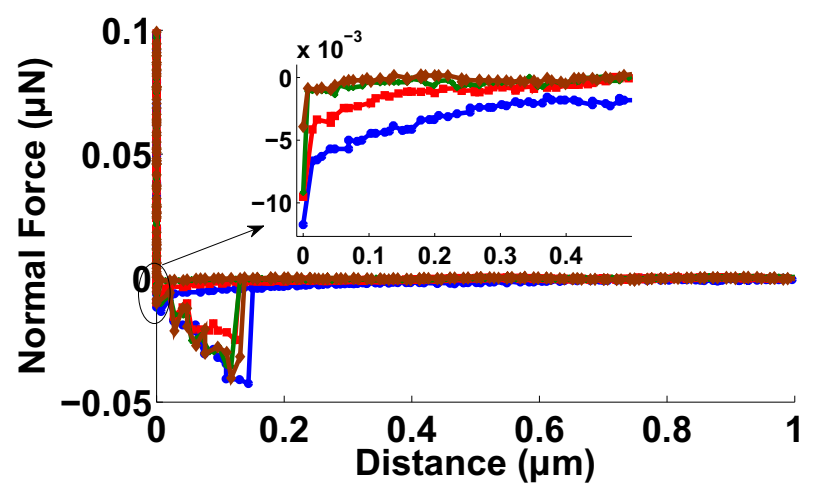

(a)

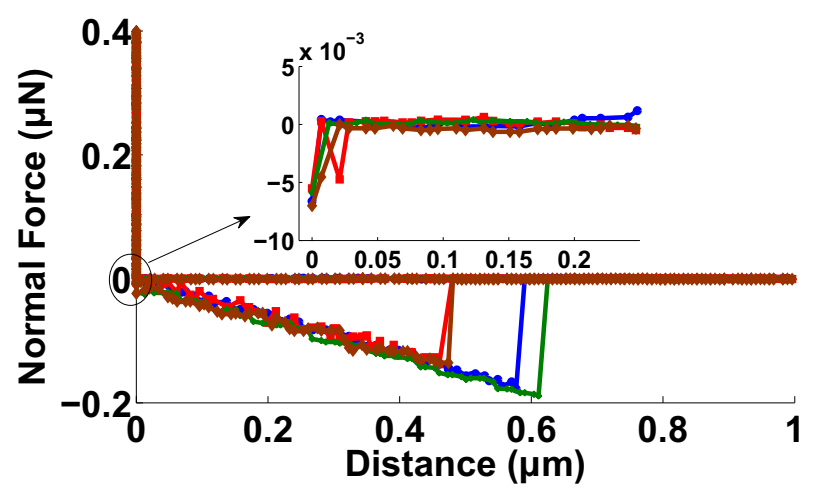

(b)

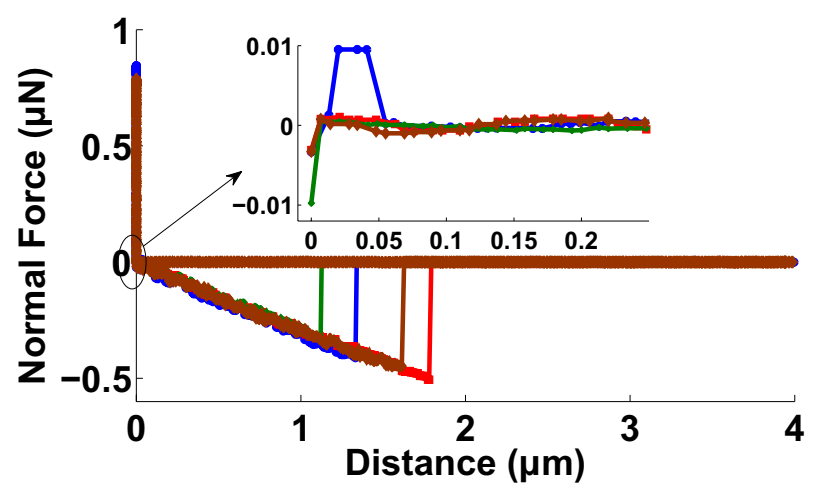

(c)

Figure 3: Force-distance curves, in dry medium, for a structured surface by differents PS latex particles size (stiffness: $0.3 \mathrm{~N} / \mathrm{m}$ ) with a radius of a) $100 \mathrm{~nm}$, b) $500 \mathrm{~nm}$, c) $1500 \mathrm{~nm}$. 
The average values of the different measurements presented in Figure 3, (pull-in and pull-off forces), for different PS latex particles size, are summarized in the Table 2.

Table 2: Influence of the PS particles size on the pull-in and pull-off forces $(\mathrm{nN})$ (stiffness 0.3 $\mathrm{N} / \mathrm{m})$.

\begin{tabular}{|c|c|c|}
\hline $\begin{array}{c}r_{2} \\
(\mathrm{~nm})\end{array}$ & $\begin{array}{c}\text { Pull-in } \\
(\mathrm{nN})\end{array}$ & $\begin{array}{c}\text { Pull-off } \\
(\mathrm{nN})\end{array}$ \\
\hline particles free silica & 0 & $>-1000$ \\
\hline 100 & $-8.7 \pm 1.5$ & $-33.5 \pm 7$ \\
\hline 500 & $-6.0 \pm 1.7$ & $-159 \pm 24$ \\
\hline 1500 & $-5.9 \pm 3.6$ & $-386 \pm 67$ \\
\hline
\end{tabular}

The PS particle deposition decreases the pull-off force compared to the uncoated silica surface (- $386 \mathrm{nN}$ as opposed to $-1 \mu \mathrm{N}$ ). The size of the PS latex particles has an important influence on the adhesion. Indeed, decreasing the size from $1500 \mu \mathrm{m}$ to $100 \mathrm{~nm}$ reduces the adhesion force nearly 10 times. However, the pull-in force, e.g. the force when two surfaces approach one another, was roughly $-6 \mathrm{~nm}$ for all the PS particles. This phenomena can be explain by the fact that the experiment was performed in air, so there are no important charges on the surface, except charges induced by humidity.

\section{Results analysis}

\section{Number of contact points}

Usually force measurements are conducted between a sphere and a planar substrate where the contact surface is necessary a unique surface. In our case, the substrate is structured with several microspheres and the contact numbers must be studied.

The relative position between the probe and the spheres on the substrate is described in Figure 4 . When the probe is approaching, it touches a first sphere $S_{a}$. The distance between the probe and the second sphere $S_{b}$ is called $z_{b}$. During force measurement, a preload force is applied on the sphere which induces a local deformation defined by the displacement $\delta$. If $\delta$ is less than the distance $z_{b}$, the probe does not touch the second sphere $S_{b}$ and the contact is a sphere-sphere 
contact.

We are going to show that in a large majority of cases, the displacement $\delta$ is negligible compared to the distance $z_{b}$. The distance $d$ between the probe and the second sphere is a function of the relative position of the probe and the PS spheres. The maximum value $z_{b \max }$ of $z_{b}$ is reached when the probe and the first sphere are aligned:

$$
z_{b} \in\left(0 ; z_{b \max }=r_{2}-\sqrt{r_{2}^{2}-2 r_{1}^{2}}\right)
$$

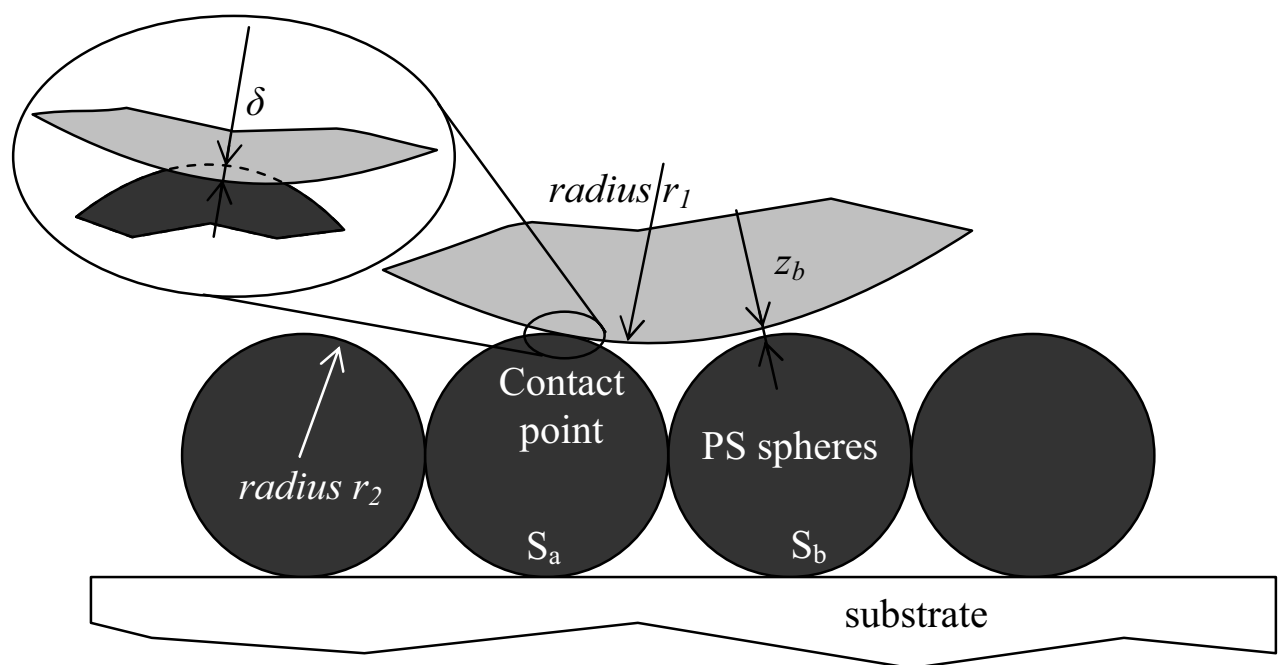

Figure 4: Description of the contact between the probe and the PS spheres on the substrate.

As the Tabor parameter, ${ }^{18}$ is from 8.6 to 19 , the JKR model ${ }^{15}$ should be considered in order to estimate the displacement $\delta$. In the case of a sphere-sphere contact, the displacement $\delta$ is given by:

$$
\begin{aligned}
\delta & =\frac{a^{2}}{r_{12}}-\sqrt{\frac{4 F_{\text {pull-off }} a}{3 E^{*} r_{12}}} \\
a^{3} & =\frac{3 r_{12}}{4 E^{*}}\left(F_{\text {ext }}+2 F_{\text {pull-off }}+2 \sqrt{F_{\text {pull-off }} F_{\text {ext }}+\left(F_{\text {pull-off }}\right)^{2}}\right)
\end{aligned}
$$

where $F_{\text {pull-off }}$ is the pull-off force and $F_{\text {ext }}$ is the external or load force applied on the 
sphere, ${ }^{22}$ the $r_{12}$ is the relative radius and $E^{*}$ is the effective Young's modulus defined by:

$$
\begin{aligned}
\frac{1}{r_{12}} & =\frac{1}{r_{1}}+\frac{1}{r_{2}}, \\
\frac{1}{E^{*}} & =\frac{1-v_{1}^{2}}{E_{1}}+\frac{1-v_{2}^{2}}{E_{2}},
\end{aligned}
$$

where $E_{i}$ and $v_{i}$ are the Young's modulus and the Poisson's coefficient of the material $i$. The values were respectively $3.2 \mathrm{GPa}$ and 0.33 for the polystyrene sphere and $71 \mathrm{GPa}$ and 0.21 for the borosilicate sphere. So, the effective Young's modulus is $\mathrm{E}^{*}=4.5 \mathrm{GPa}$.

The Table 3 describes the deformation values $\delta$ induced only by adhesion corresponds to the value of $\delta$ when the external preload $F_{\text {ext }}$ is null.

Table 3: Characterization of the contact deformation in function of the PS sphere radius.

\begin{tabular}{|c|c|c|}
\hline$r_{2}[\mathrm{~nm}]$ & $z_{b \max }[\mathrm{nm}]$ & $\delta[\mathrm{nm}]$ \\
\hline 100 & 4 & 1.4 \\
\hline 500 & 100 & 2.5 \\
\hline 1500 & $10^{3}$ & 3.4 \\
\hline
\end{tabular}

Table 3 shows that this deformation $\delta$ induced by adhesion is negligible compared to the maximal distance $z_{b \max }$. We consequently assume that the force measurements have been done on a unique contact point. Moreover as the distance between the second sphere $z_{b \max }$ is greater than the typical interaction distance $z_{0} \in[0.2 \mathrm{~nm} ; 0.4 \mathrm{~nm}]$ at the contact, only the interaction between the probe and the first sphere can be considered.

\section{Interaction force modeling}

As the pull-off force is a direct consequence of van der Waals forces between both objects, the experimental pull-off measurements can be compared with van der Waals models. ${ }^{19-21,23,24}$ This model has been chosen in spite of DMT or JKR model in order to build a model which can be easily extended in smaller spheres. Indeed, we are going to show that in case of nanosphere (radius $<100 \mathrm{~nm}$ ), the distance interaction with more that one sphere in the plane should be considered. These distance forces can only be taken into account using the van der Waals model. Based 
on, ${ }^{21}$ the impact of local deformation on the calculation of van der Waals force can be neglected in the nanoscale, thus we are considering the force between two rigid spheres:

$$
F_{v d w}=\frac{A_{12} r_{12}}{6 z_{0}^{2}}
$$

where $z_{0}$ is the contact distance and $A_{12}$ the Hamaker constant which can be calculated using the approximative combination law:

$$
A_{12}=\sqrt{A_{1} \cdot A_{2}}
$$

where $A_{i}$ is the Hamaker constant of the material $i$.

In our case, Hamaker constants of the polystyrene and of the silica are respectively $A_{1}=79 z J^{42}$ and $A_{2}=65 z J .{ }^{21}$ With these Hamaker value, the Hamaker constant of the system determined with the approximate combination law (7) is $A_{12}=72 z J$. The typical value of $z_{0}$ are between $0.2 \mathrm{~nm}$ and $0.4 \mathrm{~nm}$, we assume that $z_{0}=0.25 \mathrm{~nm}$.

The Figure 5 presents the experimental forces as a function of the radius $r_{2}$. The van der Waals force (6) based on the combination law (7) and drawn in dashed line has the same tendency as the experimental values and the maximum error is around $30 \%$. These values are also providing an opportunity to identify the Hamaker constant between polystyrene and borosilicate. An identification (RMSE optimization) has enabled the determination of the Hamaker constant:

$$
A_{12}^{i d}=1.2910^{-19} \mathrm{~J}
$$

Differences between the experimental and theoretical values of the Hamaker constant could be explained by the approximation made in the combination law (7) and also some uncertainties on the chemical composition of the silica. The van der Waals force calculated with this value is plotted as a dotted line in Figure 5. It shows that the model proposed in (6) is able to predict the pull-off force between the spherical probe and the structured substrate. 


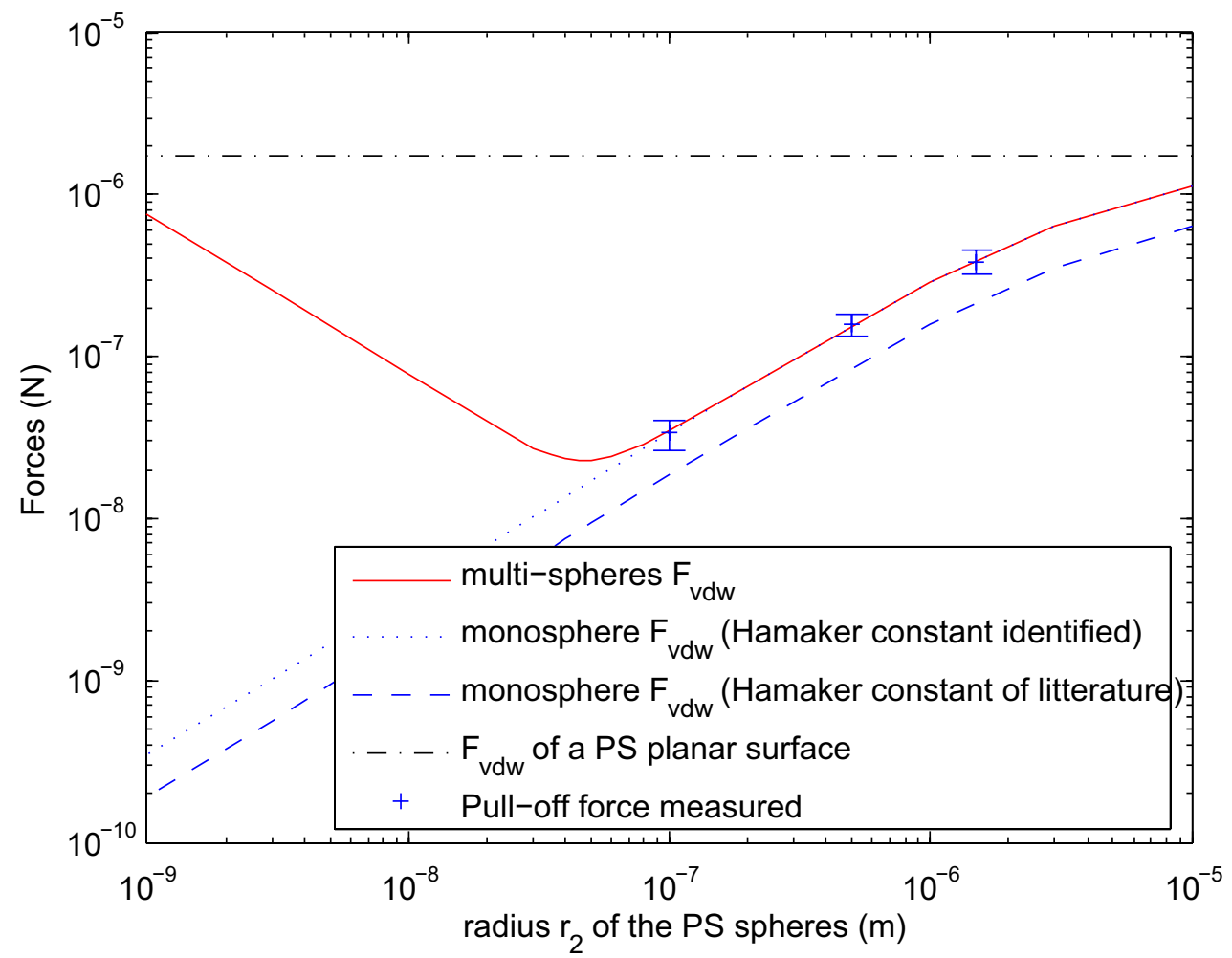

Figure 5: Experimental and theoretical forces in function of the radius $r_{2}$ of the PS spheres : the dashed and dotted blue lines represent the monosphere model of the van der Waals force based respectively on the theoretical value 7) and the identified value (8), red solid line described the multi-sphere model which is similar to the monosphere model for $r_{2}$ greater than $100 \mu \mathrm{m}$. Error bars show the experimental measurements. The decreasing of the experimental pull-off force can be predicted by the models. Moreover, the multisphere model (red line) shows that the pull-off force reaches a minimum for $r_{2}=45 \mathrm{~nm}$. Below this value, the force is increasing and is converging to a PS plane interaction (dashdot line). 


\section{Analysis of the scale effect}

Based on the model (6), the evolution of the interaction force can be extended to smaller spheres. In that case, the interaction force between the probe and the other spheres have to be considered. Let us consider the arrangement described in Figure 6, and the fact that the measurement is taken at the sphere defined by $(i=0, j=0)$. Based on a geometrical analysis, the distance $z_{i j}$ between the probe $\left(r_{1}\right)$ and a sphere $(i, j)$ is:

$$
z_{i j}=\sqrt{\left(r_{2}+z_{0}+r_{1}\right)^{2}+4 r_{2}^{2}\left(j^{2}-i j+i^{2}\right)}-r_{1}-r_{2} .
$$

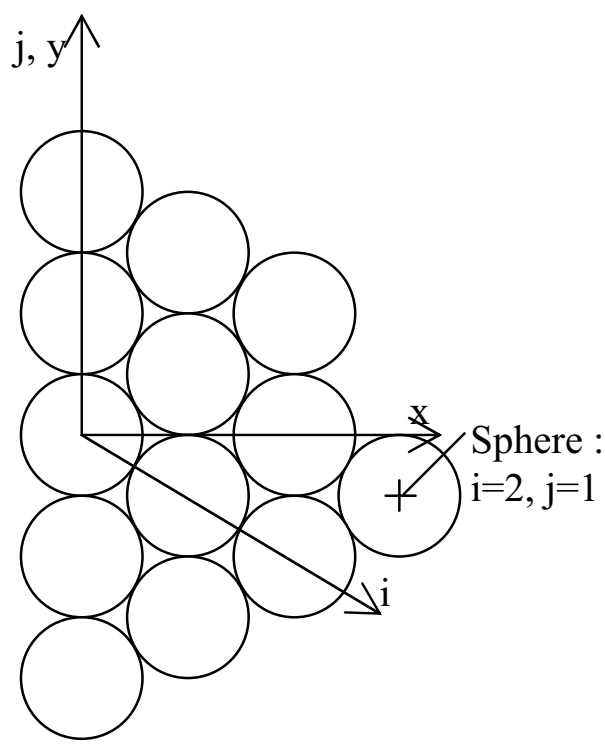

Figure 6: Arrangement of the PS spheres on the substrate.

The van der Waals force $z_{i j}$ between the probe and the sphere $(i, j)$ verifies:

$$
\left\|\vec{F}_{i j}\right\|=\frac{A r_{12}}{6 z_{i j}^{2}}
$$


The total force $F_{T v d w}$ between an infinite plan structured with PS spheres and the probe is thus:

$$
\begin{gathered}
F_{T v d w}=\sum_{i, j}^{\mathbb{Z}^{2}} \vec{F}_{i j} \cdot \vec{z} \\
F_{T v d w}=\sum_{i, j}^{\mathbb{Z}^{2}} \frac{A r_{12}}{6 z_{i j}^{2}} \cdot \frac{r_{2}+z_{0}+r_{1}}{r_{2}+z_{i j}+r_{1}}
\end{gathered}
$$

This model of the interaction between a spherical probe and a structured surface has been simulated using the Matlab Simulink software. The evolution of $F_{T v d w}$ as a function of the radius, $r_{2}$, of the sphere is drawn as a red dashed line in Figure 5. It shows that the monosphere model proposed in equation (6) is valid for $r_{2}$ larger than $100 \mathrm{~nm}$. For radii below $100 \mathrm{~nm}$, the force induced by the spheres around the contact sphere cannot be neglected. The second results deals with the determination of a minimum of the interaction force which represents an optimum of adhesion reduction in the applicative field of micromanipulation. In our experimental case, the optimum radius $r_{2}$ in order to minimize the adhesion is $45 \mathrm{~nm}$. This value depends of the diameter of borosilicate sphere glue to the cantilever. We can extend the model to different diameter of borosilicate sphere. If the radius is lower than this optimum, more and more spheres should be considered in the sum (12), thus increasing the force. As the sphere radius approach $1 \mathrm{~nm}$, the total force approaches the theoretical interaction force with a uniform planar surface of PS. It is possible to show that the interaction force between the substrate above the PS sphere and the borosilicate sphere is negligible for PS spheres whose radius $r_{2}$ is larger that $1 \mathrm{~nm}$. For example, for small PS spheres whose radius is $r_{2}=5 \mathrm{~nm}$, the force $F_{T v d w}$ is $1.55 e-7 \mathrm{~N}$ and the interaction force between the borosilicate sphere 1 and the substrate above the PS spheres is $4.2 e-9 \mathrm{~N}$.

We note here that researchers have developed arrays of polymer pillars ${ }^{43}$ and vertically aligned carbon nanotubes ${ }^{44}$ that stick firmly to surfaces. ${ }^{45}$ These surface structuring could validate our model that by decreasing the diameter of the PS spheres, we increase the adhesion forces. However, more experiment are in progress in order to synthesize PS spheres monolayer with diameter less 
than $100 \mathrm{~nm}$ and to study the adhesion forces on these monolayers.

The optimum radius $r_{2}$ and the minimal adhesion force obtained depends also on the radius $r_{1}$ of the borosilicate sphere. Figure 7 presents the simulation of the minimal pull-off force and the polystyrene radius $r_{2}$ associated versus the borosilicate radius $r_{1}$. In an applicative point of view, in micromanipulation, the pull-off force between the gripper and the object must be minimal. For each radius $r_{1}$ of manipulated borosilicate microspheres Figure 5 gives the optimal radius $r_{2}$ of the PS structuration of the gripper and the pull-off force obtained. The contact pressure $F_{T v d w} / \pi a^{2}$ is also described on the Figure 7. Consequently, this Figure 7 represents a relevant tool for the design of the surface structuration of microgrippers.

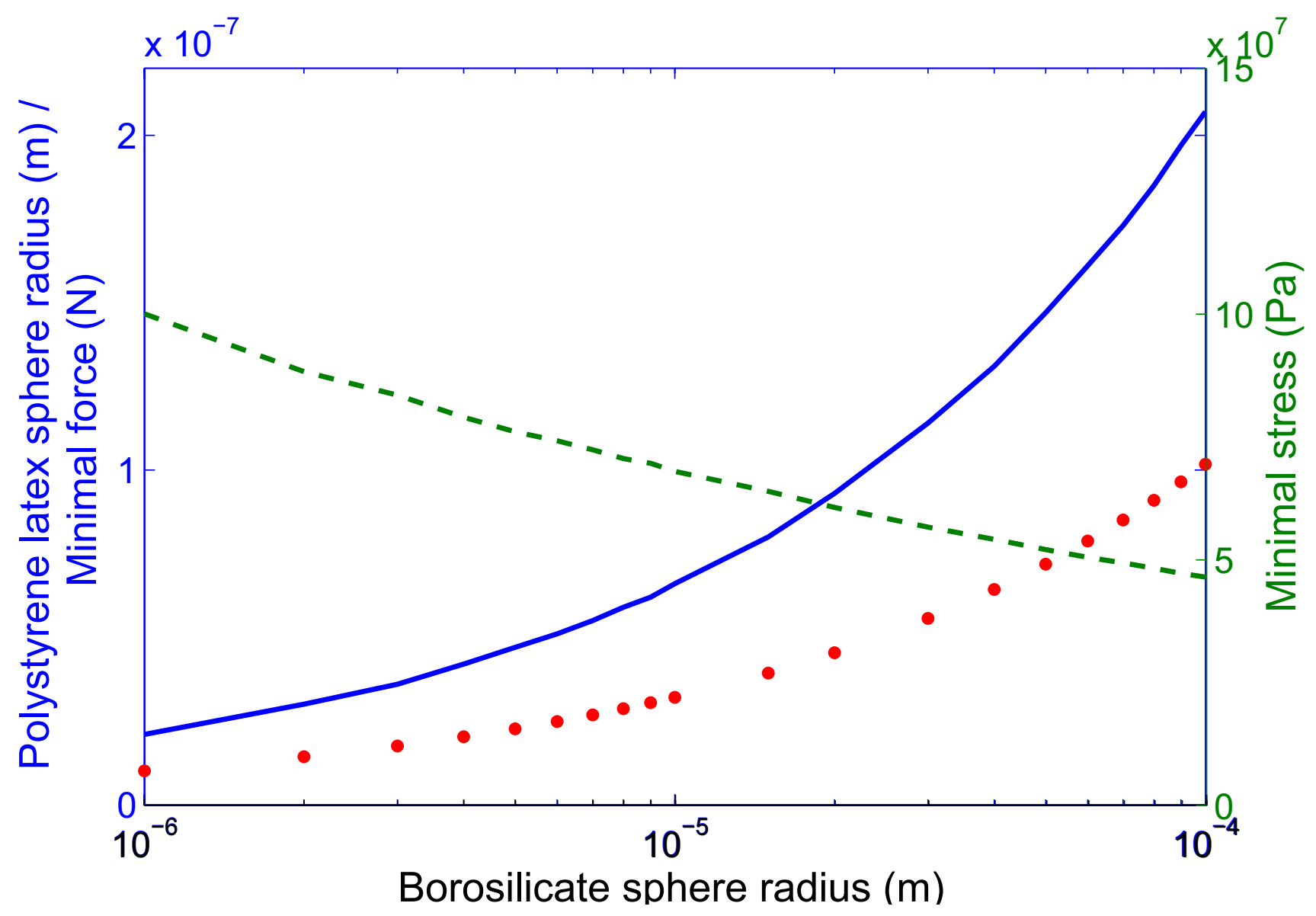

Figure 7: Simulation of the borosilicate radius influence on polystyrene latex sphere radius in order to obtain the minimal adhesion force. Minimal adhesion force variation (red dotted line), polystyrene latex radius obtained (blue solid line), and stress (green dashed lines) versus the borosilicate sphere. 


\section{Conclusion}

In this communication, we have studied the interaction behaviour, and most precisely the adhesion force, between a structured surface and a borosilicate sphere. The experiments were performed as a function of the polystyrene latex particle radii from 100 to $1500 \mathrm{~nm}$ deposited on the silica substrate. The PS sphere size influences the pull-off force, and the experimental decreasing of PS size decreases the adhesion force near 100 times compared to a uncoated substrate. A van der Waals model computing a mono or multisphere approach and measurements were compared and show a good agreement with a maximal error less than $30 \%$. Based on the model, we have shown that the adhesion force could be minimized with a PS latex particle radius near to $45 \mathrm{~nm}$.

More experiments are in progress in order to confirm this model. Because adhesion is the current highest disturbance in micromanipulation (positioning and release), structured surface is a promising way to improve micro-object manipulation in the future. This paper provides design rules to structure gripper surface in order to minimize adhesion. A wide range of applications, in the field of telecommunications, bioengineering, and more generally speaking MEMS can be also envisaged for these substrates.

\section{Acknowledgement}

This work was supported by the EU under HYDROMEL (contract NMP2-CT-2006-026622): Hybrid ultra precision manufacturing process based on positional- and self-assembly for complex micro-products, and by the French National Agency (ANR) under NANOROL (contract ANR-07ROBO-0003): Nanoanalyse for micromanipulate. We would also like to acknowledge the support of Dr. Zhao WANG, EMPA, for their interaction model correction.

\section{References}

(1) Tamadazte, B.; Dembélé, S.; Le Fort-Piat, N. Sens. Transducers J. 2009, 5, 37-52. 
(2) Lambert, P. Capillary Forces in Micro-assembly; Springer: Amsterdam, The Netherlands, 2008.

(3) Gauthier, M.; Régnier, S.; Rougeot, P.; Chaillet, N. J. Micromech. 2006, 3, 389-413.

(4) Zhou, Q.; Chang, B.; Koivo, H. N. Ambient environment effects in micro/nano handling. Proceeding of the International Workshop on Microfactories, Shangai, China, Oct 15-17, 2004; IOP Publishing Ltd.: Bristol, U.K., 2004; pp 146-51.

(5) Hériban, D.; Gauthier, M. Robotic Micro-assembly of Microparts Using a Piezogripper. Proceeding of the 2008 IEEE/RSJ International Conference on Intelligent Robots and Systems, Nice, France, Sept 22-26, 2008; 2008; pp 4042-4047.

(6) Dafflon, M.; Lorent, B.; Clavel, R. A micromanipulation setup for comparative tests of microgrippers. International Symposium on Robotics (ISR),Rio de janeiro, Brazil, July 6-10, 2006; 2006. CD-ROM; available on-line on EPEL website..

(7) Blomberg, E.; Poptoshev, E.; Claesson, P. M.; Caruso, F. Langmuir 2004, 20, 5432-5438.

(8) Charrault, E.; Gauthier, C.; Marie, P.; Schirrer, R. Langmuir 2009, 25, 5847-5854.

(9) Dejeu, J.; Rougeot, P.; Gauthier, M.; Boireau, W. Micro Nano Lett 2009, 4, 74-79.

(10) Wang, T.; Canetta, E.; Weerakkody, T. G.; Keddie, J. L. ACS Appl. Mater. Interfaces 2009, 1, $631-639$.

(11) Gong, H.; Garcia-Turiel, J.; Vasilev, K.; Vinogradova, O. I. Langmuir 2005, 21, 7545-7550.

(12) Rabenorosoa, K.; Clevy, C.; Lutz, P.; Gauthier, M.; Rougeot, P. Micro Nano Lett. 2009, 4, $148-154$.

(13) Vajpayee, S.; Hui, C.-Y.; Jagota, A. Langmuir 2008, 24, 9401-9409.

(14) Murphy, M. P.; Kim, S.; Sitti, M. ACS Appl. Mater. Interfaces 2009, 1, 849-855. 
(15) Johnson, K. L.; Kendall, K.; Roberts, A. D. Proc. R. Soc. Lond. A 1971, 324, 301-313.

(16) Derjaguin, B. V.; Muller, V.; Toporov., Y. P. J. Colloid Interface Sci. 1975, 53, 314-326.

(17) Maugis, D. J. Colloid Interface Sci. 1992, 150, 243-269.

(18) Maugis., D. Contact, adhesion and rupture of elastic solids.; Springer: Springer Series in Solid-State Sciences; Springer-Verlag Berlin Heidelberg New York, 2000.

(19) Hamaker, H. C. Physica 1937.

(20) Delrio, F. W.; Boer, M. P. D.; Knapp, J. A.; Davidreedy, E.; Clews, P. J.; DUNN, M. L. Nat. Mater. 2005, 4, year.

(21) Alvo, S.; Lambert, P.; Gauthier, M.; Régnier, S. J. Adhes. Sci. Technol. 2010, in press.

(22) Israelachvili, J. Intermolecular and Surface forces 1991, Academic Press, second edition.

(23) Thoreson, E.; Martin, J.; Burnham, N. J. Colloid Interface Sci. 2006, 298, 94-101.

(24) Li, Q.; Rudolph, V.; Peukert, W. Powder Technol. 2006, 161, 248-255.

(25) Dejeu, J.; Rougeot, P.; Gauthier, M.; Boireau, W. ACS Appl. Mater. Interfaces 2009, 1, 19661973.

(26) Li, J.; Fu, J.; Cong, Y.; Wu, Y.; Xue, L. J.; Han, Y. C. Appl. Surf. Sci. 2006, 252, 2229-2234.

(27) Kim, S. H.; Kim, J. H.; Kang, B. K.; H. S. Uhm, . . Langmuir 2005, 21, 12213-12217.

(28) Han, J. T.; Zheng, Y.; Cho, J. H.; Xu, X.; Cho, K. J. Phys. Chem. B 2005, 109, 20773-20778.

(29) Zhao, N.; Shi, F.; Wang, Z. Q.; Zhang, X. Langmuir 2005, 21, 4713-4716.

(30) Shi, F.; Wang, Z. Q.; Zhang, X. Adv. Mater. 2005, 17, 1005-1009.

(31) Han, J. T.; Lee, D. H.; Ryu, C. Y.; Cho, K. W. J. Am. Chem. Soc. 2004, 126, 4796-4797. 
(32) Hikita, M.; Tanaka, K.; Nakamura, T.; Kajiyama, T.; Takahara, A. Langmuir 2005, 21, 7299_ 7302.

(33) Jiang, L.; Zhao, Y.; Zhai, J. Angew. Chem., Int. Ed. 2004, 43, 4338-4341.

(34) Gu, Z. Z.; Wei, H. M.; Zhang, R. Q.; Han, G. Z.; Pan, C.; Zhang, H.; Tian, X. J.; Chen, Z. M. Appl. Phys. Lett. 2005, 86, 201915.

(35) Deckman, H.; Dunsmuir, J. Appl. Phys. Lett. 1982, 41, 377.

(36) Sakamoto, S.; Philippe, L.; Bechelany, M.; Michler, J.; Asoh, H.; Ono, S. Nanotechnology 2008, 19, 405304-405309.

(37) Bechelany, M.; Brodard, P.; Philippe, L.; Michler, J. Nanotechnology 2009, 20, 455302455309.

(38) Bechelany, M.; Maeder, X.; Riesterer, J.; Hankache, J.; Lerose, D.; Christiansen, S.; Michler, J.; Philippe, L. Cryst. Growth Des. 2010, 587-596.

(39) Elias, J.; Lévy-Clément, C.; Bechelany, M.; Michler, J.; Wang, G.-Y.; Wang, Z.; Philippe, L. Adv. Mater. 2010, 22, 1607-1612.

(40) Mook, W.; Niederberger, C.; Bechelany, M.; Philippe, L.; Michler, J. Nanotechnology 2010, 21,55701 .

(41) Huang, Z.; Fang, H.; Zhu, J. Adv. Mater. 2007, 19, 744-748.

(42) Parsegian, A. van der Waals forces: a handbook for biologists, chemists, engineers, and Physicists.; Cambridge University Press: New York, USA, 2005.

(43) Geim, A. K.; Dubonos, S. V.; Grigorieva, I. V.; Novoselov, K. S.; Zhukov, A. A.; Shapoval, S. Yu. Nat. Mater. 2003, 2, 461-463.

(44) Qu, L.; Dai, L.M. Adv. Mater. 2007, 19, 3844-3849. 
(45) Wang, Z.L.. Nat. Nanotechnol. 2009, 4, 407-408

\section{List of Figures}

1 Attractive and adhesive typical force-distance curves between surface and cantilever $($ stiffness: $0.3 \mathrm{~N} / \mathrm{m}) \ldots \ldots \ldots \ldots \ldots \ldots$

2 SEM images of a self assembled monolayer of PS spheres with a radius of (a) 100 $\mathrm{nm}$, (b) $500 \mathrm{~nm}$ and (c) $1500 \mathrm{~nm} \ldots \ldots \ldots \ldots$

3 Force-distance curves, in dry medium, for a structured surface by differents PS latex particles size (stiffness: $0.3 \mathrm{~N} / \mathrm{m}$ ) with a radius of a) $100 \mathrm{~nm}$, b) $500 \mathrm{~nm}, \mathrm{c}$ )

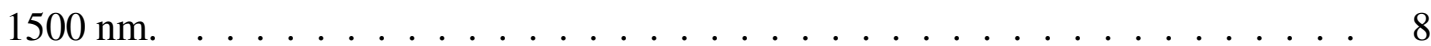

4 Description of the contact between the probe and the PS spheres on the substrate. . 10

5 Experimental and theoretical forces in function of the radius $r_{2}$ of the PS spheres : the dashed and dotted blue lines represent the monosphere model of the van der Waals force based respectively on the theoretical value 7) and the identified value (8), red solid line described the multi-sphere model which is similar to the monosphere model for $r_{2}$ greater than $100 \mu \mathrm{m}$. Error bars show the experimental measurements. The decreasing of the experimental pull-off force can be predicted by the models. Moreover, the multisphere model (red line) shows that the pull-off force reaches a minimum for $r_{2}=45 \mathrm{~nm}$. Below this value, the force is increasing and is converging to a PS plane interaction (dashdot line) . . . . . . . . . . . . 13

6 Arrangement of the PS spheres on the substrate . . . . . . . . . . . . . . . . 14

7 Simulation of the borosilicate radius influence on polystyrene latex sphere radius in order to obtain the minimal adhesion force. Minimal adhesion force variation (red dotted line), polystyrene latex radius obtained (blue solid line), and stress (green dashed lines) versus the borosilicate sphere. . . . . . . . . . . . . . . . . . 16 
Table of Contents Graphic

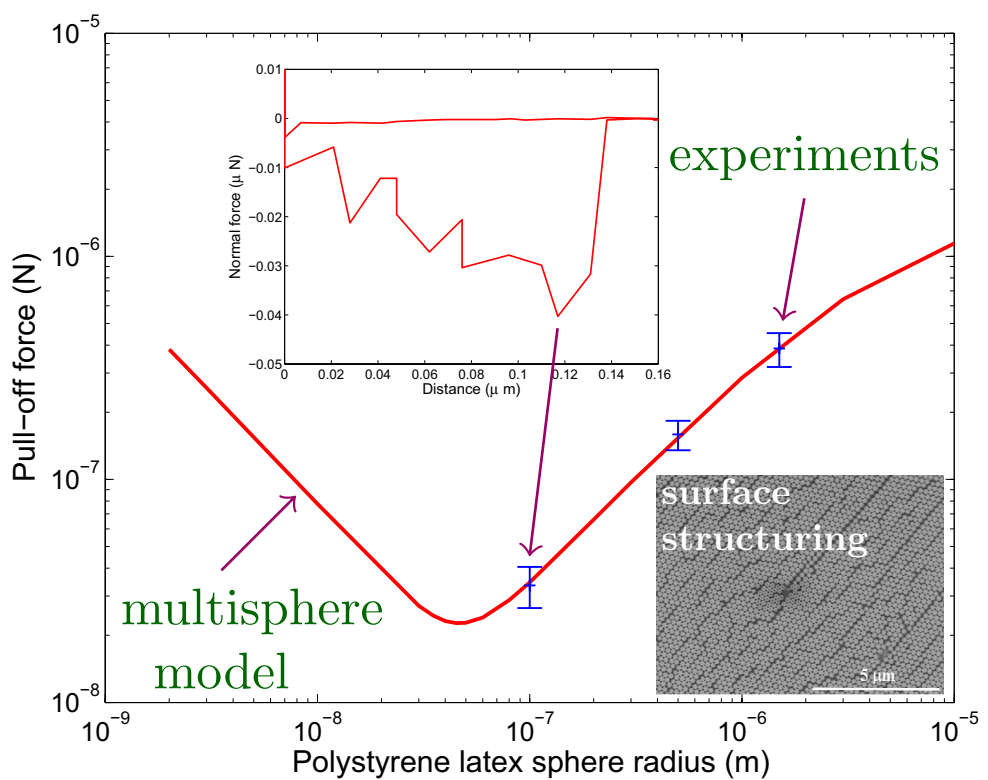

